\title{
Supplementation with 200 mg/Day \\ Docosahexaenoic Acid from Mid-Pregnancy through Lactation Improves the Docosahexaenoic Acid Status of Mothers with a Habitually Low Fish Intake and of Their Infants
}

\author{
Renate L. Bergmann ${ }^{a}$ Elisabeth Haschke-Becher ${ }^{\text {b }}$ \\ Petra Klassen-Wigger ${ }^{c}$ Karl E. Bergmann ${ }^{a}$ Rolf Richter ${ }^{a}$ \\ Joachim W. Dudenhausen ${ }^{a}$ Dominik Grathwohlc Ferdinand Haschke ${ }^{c}$ \\ a Department of Obstetrics, Charité Universitätsmedizin Berlin, Berlin, Germany; ${ }^{b}$ Central Laboratory of the \\ University Hospital of Neurology Salzburg, Paracelsus Medical Private University, Salzburg, Austria; \\ 'Nestlé Nutrition Institute, Vevey, Switzerland
}

\section{Key Words}

Supplements · Docosahexaenoic acid • Pregnancy • Lactation $\cdot$ Concentration $\cdot$ Erythrocytes $\cdot$ Breast milk

\begin{abstract}
Background/Aims: The supply of docosahexaenoic acid (DHA, 22:6w-3), important for fetal/infant neurodevelopment, depends on the maternal fatty acid (FA) status, which may be marginal in central Europe. Therefore, we investigated the effect of a daily vitamin/mineral supplement with and without 200 mg DHA from mid-pregnancy through lactation on the DHA concentrations in maternal and infant red blood cell phospholipids (RBC\%), and in breast milk FA (\%). Methods: At 21 weeks' gestation, 144 women were enrolled into a randomised, double-blind clinical trial receiving daily: (1) a basic vitamin-mineral supplement (Vit/Min group), (2) Vit/Min plus $4.5 \mathrm{~g}$ fructo-oligosaccharide (FOS group), or (3) Vit/Min plus $4.5 \mathrm{~g}$ FOS plus $200 \mathrm{mg}$ fish oil-derived DHA (DHA-FOS group). FAs were determined by capillary gas-liq-
\end{abstract}

\section{KARGER \\ Fax +4161306 1234 \\ E-Mail karger@karger.ch}

www.karger.com (c) 2008 S. Karger AG, Basel

0250-6807/08/0522-0157\$24.50/0

Accessible online at:

www.karger.com/anm uid chromatography. Results: While maternal RBC-DHA\% at enrolment was not different, at 37 weeks gestation, and 3 months after delivery RBC-DHA\% were significantly higher in the DHA-FOS group. The breast milk DHA\% was twice as high in the DHA-FOS group (0.50\%) than in the two others $(0.25 \%)(p<0.001)$, and the ratio ARA/DHA in the DHA-FOS group was $1.0 \pm 0.43$, in the others $2.1 \pm 0.43(p<0.001)$. The RBC-DHA\% of the infants in the DHA-FOS group was also significantly higher, and correlated significantly with maternal RBC-DHA\% before and 3 months after delivery. Conclusions: In central Europe, a dose of $200 \mathrm{mg} /$ day DHA from mid-pregnancy through lactation seems appropriate to improve the DHA status of mothers and infants.

Copyright $\odot 2008$ S. Karger AG, Basel

External funding was from Nestec Ltd., Switzerland (trial No. 99.43. INF), supported by additional research funds of the Charité University Hospitals.
Prof. Dr. Renate Bergmann

Department of Obstetrics, Charité Universitätsmedizin, Campus Virchow Augustenburger Platz 1

DE-13353 Berlin (Germany)

Tel. + 4930450 64101, Fax +493045064908, E-Mail renate.bergmann@charite.de 


\section{Introduction}

Nutritional supplementation with critical or multimicronutrients is recommended for women before conception, during pregnancy and lactation, even in affluent societies [1-4]. Recently, micronutrients for pregnant women are also provided together with functional food supplements such as docosahexaenoic acid (DHA) or prebiotics [5-7].

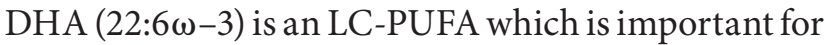
the development of the brain and retina in mammals, and is considered to be essential for the human fetus and infant $[8,9]$. The DHA stores increase in maternal fat depots during early pregnancy and become available for placental transfer in late pregnancy, when fetal fat accretion and brain growth increase exponentially $[10,11]$. It has been shown in different countries that in the second half of pregnancy maternal DHA stores decrease, which results in a suboptimal DHA supply of the fetus and the neonate [12-14]. Dietary DHA supplements in the second and third trimester improved the DHA status of the mother as indicated by her red blood cell (RBC) fatty acid composition [14-16]. After birth, RBC-DHA concentrations decrease in lactating more than in nonlactating mothers, and breast milk-DHA concentrations fall steadily during the months after delivery $[12,15,17,18]$. Supplements with a DHA content between 0.2 and $1.2 \mathrm{~g} /$ day during pregnancy and/or lactation increased the DHA concentration in breast milk lipids in a dose-response manner [19-29]. Although no official recommendation for a supplementation of $\omega-3$ fatty acids during pregnancy and lactation has been released so far, expert panels recommended ensuring a DHA intake of $100-300 \mathrm{mg} /$ day [30-32].

Prebiotics, like fructo-oligosaccharides (FOS), are nondigestible food ingredients that beneficially affect the host by selectively stimulating the growth and/or activity of one or a limited number of bacteria in the colon and thus improve host health $[33,34]$. Prebiotics and probiotics may modulate lipid metabolism, and possibly increase maternal DHA status [34, 35].

The aim of this study was to examine if the DHA status of pregnant and lactating women with a relatively low habitual fish consumption could be sufficiently and safely elevated by the addition of $200 \mathrm{mg} /$ day of DHA to their vitamin-mineral supplement (with or without FOS) in order to improve the DHA status of their breast-fed infants.
Table 1. Composition of the basic nutritional supplement for pregnant and lactating women, a skim milk-based, acidified liquid in a $200-\mathrm{ml}$ tetrabox (Vit/Min group)

\begin{tabular}{lll}
\hline & Per 100 g liquid & Per daily serving \\
\hline Energy, kcal/kJ & 59 & 120 \\
Protein, g & 2.3 & 4.6 \\
Carbohydrates, g & 12.4 & 24.8 \\
Dietary fiber, g & 0.48 & 0.96 \\
Minerals $($ ash), g & 0.85 & 1.69 \\
Sodium, mg & 33 & 66 \\
Potassium, mg & 155 & 308 \\
Chloride, mg & 80 & 159 \\
Calcium, mg & 200 & 398 \\
Phosphorus, mg & 105 & 209 \\
Magnesium, mg & 38 & 76 \\
Selenium, mg & 5.0 & 10.0 \\
Micronutrients & & \\
$\beta$-Carotene, $\mu \mathrm{g}$ & 1,050 & 2,100 \\
Vitamin $\mathrm{D}, \mu \mathrm{g}$ & 2.5 & 5.0 \\
Vitamin $\mathrm{E}, \mathrm{IU}$ & 3.0 & 6.0 \\
Vitamin C, mg & 25 & 50 \\
Vitamin $\mathrm{B}_{1}, \mathrm{mg}$ & 0.75 & 1.5 \\
Vitamin $\mathrm{B}_{2}, \mathrm{mg}$ & 0.85 & 1.7 \\
Niacin, mg & 8.0 & 16 \\
Vitamin $\mathrm{B}_{6}, \mathrm{mg}$ & 0.7 & 1.4 \\
Folic acid, $\mu \mathrm{g}$ & 200 & 400 \\
Vitamin $\mathrm{B}_{12}, \mu \mathrm{g}$ & 0.75 & 1.5 \\
Biotin, $\mu \mathrm{g}$ & 35 & 70 \\
Iron, mg & 7.5 & 15 \\
Iodine, $\mu \mathrm{g}$ & 100 & 200 \\
Copper, mg & 0.13 & 0.26 \\
Zinc, mg & 2.5 & 5.0 \\
\hline
\end{tabular}

$4.5 \mathrm{~g}$ FOS was added to this basic supplement in the FOS group, and $4.5 \mathrm{~g}$ FOS plus $0.6 \mathrm{~g}$ fish oil containing $200 \mathrm{mg}$ DHA (low EPA, provided by FIS S.A., Switzerland) were added in the DHAFOS group.

\section{Subjects and Methods}

Study Design

The study was a randomized, controlled double-blind clinical trial of 3 dietary supplement groups. The primary objective was to investigate the effect of a daily intake of $200 \mathrm{mg}$ DHA from 21 to 37 weeks of pregnancy on red blood cell phospholipid concentrations (RBC-DHA\%) in women at 37 weeks of gestation. The intake of the supplement after delivery and the further participation of the subjects were optional. Secondary objectives therefore were to evaluate the influence of the supplement on RBC-DHA\% of the mother and her infant 3 months after delivery, and on the DHA concentration of the breast milk lipids (DHA\%). The sample size was calculated for a relevant difference on primary outcome after log transformation of 0.6 , a population standard deviation of 0.7 , an anticipated drop-out rate of $30 \%$, an alpha of $0.05 / 2$ (two tests) and a power of $90 \%$ to comprise 144 subjects, i.e. 48 in each group. 


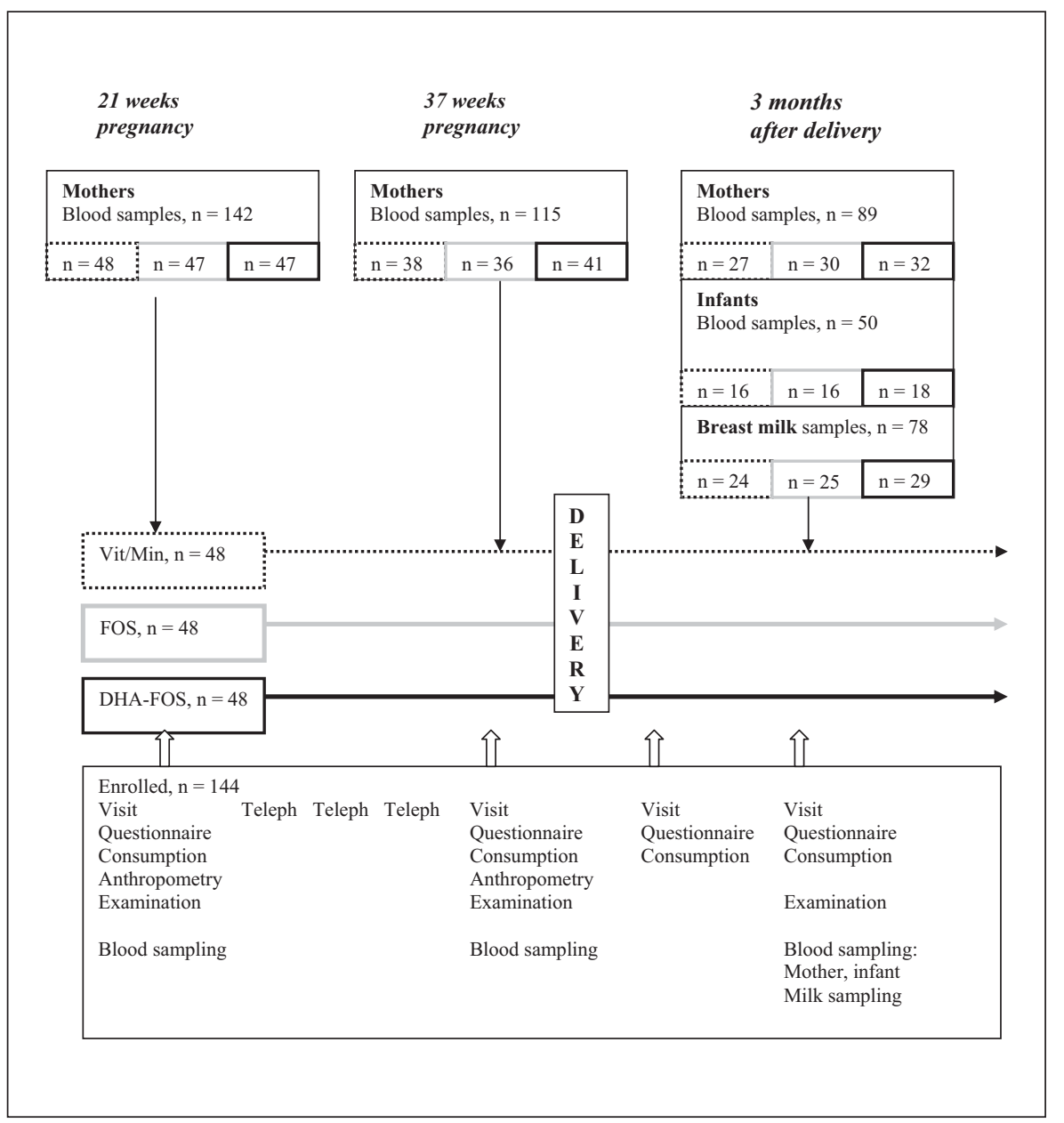

Fig. 1. Study design.

Prospective mothers were randomized in blocks by a computer program and allocated to one of three groups. The product was delivered in tetraboxes, each box (daily serving) containing 200 $\mathrm{ml}$ of a flavored and acidified milk-based supplement, and additionally vitamins and minerals composed to ensure adequate dietary intakes for pregnant and lactating women (table 1) [36]. The first group received this basic supplement (Vit/Min group). The second group received the basic supplement plus $4.5 \mathrm{~g}$ FOS to promote a favorable gut flora (FOS group). The third group received the basic supplement with FOS and $200 \mathrm{mg}$ DHA, prepared from low EPA fish oil (provided by FIS S.A., Switzerland) (DHA-FOS group). The identity of supplements was blinded to the subjects, support staff and investigators. All supplements were prepared and donated by Nestlé (Vevey, Switzerland), and were taken by the prospective mothers from the day of enrolment until 37 weeks of pregnancy, and then from the second week after delivery to the end of the third month of lactation.

\section{Subjects}

144 healthy pregnant Caucasian women who were at least 18 years of age and prepared to breast-feed for at least 3 months were enrolled at 21 weeks of gestation from October 2000 to $\mathrm{Au}$ - gust 2002 (intention to treat (ITT) data set). Exclusion criteria for prospective mothers were severe disease, age $<18$ years, non-Caucasian, increased risk of premature delivery or multiple pregnan$c y$, allergy to cow's milk protein, lactose intolerance, diabetes, smoking, consumption of alcohol (>20 g/week), participation in another study, or consuming other supplements. Infants were excluded from the study if they were premature at birth $(<37$ weeks of gestation), had any major malformations, or were hospitalized for more than 1 week. The women were recruited by obstetric-gynecological offices across Berlin or by the consulting service for pregnant women at Virchow-Klinikum of Charité. The study protocol was approved by the ethical committee of the Medical Faculty of the Humboldt University of Berlin on August 17, 2000. Written informed consent was obtained from prospective mothers for all procedures prior to enrolment.

\section{Data Collection}

Data collection and physical examinations were carried out at 21 and 37 weeks of gestation, at delivery, and at 1 and 3 months after delivery (fig. 1). At 26, 30 and 34 weeks of gestation participants were contacted by phone and asked about health problems, bowel movements and supplement consumption. Blood samples 
Table 2. Characteristics of the mothers of the three supplement groups at enrolment, ITT data set $(\mathrm{n}=144)$

\begin{tabular}{|c|c|c|c|c|}
\hline & \multicolumn{4}{|c|}{ Supplement group } \\
\hline & $\begin{array}{l}\text { Vit/Min } \\
(\mathrm{n}=49)\end{array}$ & $\begin{array}{l}\text { FOS } \\
(n=47)\end{array}$ & $\begin{array}{l}\text { DHA-FOS } \\
(\mathrm{n}=48)\end{array}$ & $\mathrm{p}$ \\
\hline Age, years & $30.0 \pm 4.62$ & $31.3 \pm 4.71$ & $30.9 \pm 4.63$ & 0.348 \\
\hline Weight before pregnancy, kg & $64.4 \pm 11.73$ & $63.6 \pm 9.23$ & $62.5 \pm 12.25$ & 0.699 \\
\hline Height, $\mathrm{cm}$ & $168.1 \pm 6.74$ & $169.3 \pm 5.62$ & $167.7 \pm 6.81$ & 0.430 \\
\hline Pre-pregnancy BMI & $23.0 \pm 5.16$ & $22.2 \pm 2.82$ & $22.2 \pm 4.29$ & 0.555 \\
\hline Parity $\geq 1, \%$ & $28(57.1)$ & $24(51.1)$ & $22(45.8)$ & 0.537 \\
\hline Married, \% & $26(53.1)$ & $27(57.4)$ & $27(56.3)$ & 0.904 \\
\hline German, \% & $46(93.9)$ & $41(87.2)$ & $45(93.8)$ & 0.408 \\
\hline Employed, \% & $35(85.4)$ & $30(78.9)$ & $31(77.5)$ & 0.634 \\
\hline 13 years of schooling, $\%$ & $28(57.1)$ & $32(68.1)$ & $32(66.7)$ & 0.476 \\
\hline
\end{tabular}

All applicable values are given as mean \pm SD.

No significant difference between groups (one-way ANOVA).

were taken from mothers at 21 and 37 weeks of gestation and 3 months after delivery. Maternal breast milk samples and blood samples of their infants were taken at 3 months after delivery.

Demographic data and the medical histories of mothers and infants were obtained by questionnaire, interviews, and birth documents [37]. Supplement consumption data was obtained through product intake diaries filled in by participating mothers.

Venous blood was collected in EDTA-conditioned tubes from the cubital vein of the mother or from a superficial vein of the infant after applying a local anesthetic. A sample of breast milk was collected by the mother by interrupting a breast-feeding and expressing $20 \mathrm{ml}$ milk manually into a plastic bottle. Milk samples were stored at $-70^{\circ} \mathrm{C}$.

\section{Laboratory Methods}

Red blood cells were separated from the plasma, cooled, washed three times in an isotonic EDTA solution, stored at $-70^{\circ} \mathrm{C}$ and shipped in dry ice to the laboratory. The erythrocyte lipids were extracted from the cells with a modification of the Folch method, the phospholipids isolated, purified, methylated and the fatty acid methyl esters determined by gas-liquid chromatography [38]. Milk fatty acid methyl esters were prepared by direct methylation of milk, and then determined like the RBC fatty ac-

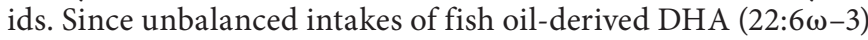
and eicosapentaenoic acid (EPA 20:6 $\omega-3$ ) may decrease the es-

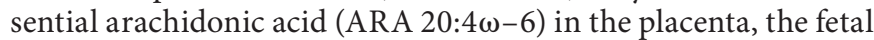
liver and brain [39], the concentrations of these three fatty acids (FA) were measured, and calculated as weight percentage of red blood cell (RBC) fatty acids in the phospholipid fraction $(\mathrm{g} / 100 \mathrm{~g}$ FA or $\%)$ or of milk FA (g/100 ml FA or wt\%).

\section{Statistical Methods}

Statistical testing of differences in RBC and breast milk fatty acids was done by ANCOVA utilizing the ITT data set and correcting for the corresponding initial RBC concentrations. Tukey adjustments were applied for multiple testing. Differences between baseline characteristics of the three treatment groups were done by ANOVA for continuous variables and by $\chi^{2}$ test for nominal variables. Student's t test for paired samples was used to compare the RBC-FA concentrations between two time points. Pearson correlation coefficients were calculated to describe the relation between maternal RBC and milk DHA\% and infant RBCDHA\%. We also used nonlinear regression analyses and fitted a linear and a cubic function to describe this relation. The declines in breast-feeding rates in the groups were compared with KaplanMeier survival analysis. All analyses were done with SPSS12.0G for Windows. $\mathrm{p}<0.05$ was regarded as statistically significant.

\section{Results}

Of 144 mothers enrolled, 142 blood samples were attained at 21 weeks of gestation. There was no significant difference in baseline characteristics of the mothers in the three supplement groups at enrolment (table 2). The course and outcome of pregnancy, e.g. maternal pregnancy weight gain, delivery mode and newborn characteristics were not different between the three supplement groups (table 3). One newborn was 35 weeks' gestational age (DHA-FOS group), and not excluded.

The mean consumption of the supplements over the whole period was not significantly different between the three groups, i.e. $83 \%$ (41-100\%), 83\% (14-98\%), and 87\% (57-98\%) of the prescribed amounts in the Vit/Min, FOS, and DHA-FOS groups, respectively.

There was no significant difference in breast-feeding rates between the three groups. $80 \%$ of the infants were exclusively breast-fed up to 3 months in either group. 
Table 3. Pregnancy characteristics, outcome and characteristics of the newborns of the three supplement groups $(\mathrm{n}=116)$ : one boy was born premature in the DHA-FOS group (35 gestational weeks)

\begin{tabular}{lccrr}
\hline \multicolumn{4}{l}{ Supplement group } & \\
\cline { 2 - 5 } & $\begin{array}{l}\text { Vit/Min } \\
(\mathrm{n}=37)\end{array}$ & $\begin{array}{l}\text { FOS } \\
(\mathrm{n}=36)\end{array}$ & $\begin{array}{l}\text { DHA-FOS } \\
(\mathrm{n}=43)\end{array}$ & $\mathrm{p}$ \\
\hline Gestational weight gain at 21-37 weeks, kg & $8.7 \pm 4.02(29)$ & $9.7 \pm 2.90(31)$ & $9.4 \pm 3.71$ & 0.518 \\
Length of gestation, weeks & $39.6 \pm 2.08(36)$ & $39.5 \pm 1.65$ & $39.0 \pm 1.64$ & 0.220 \\
Spontaneous delivery, n (\%) & $25(67.6)$ & $28(80.0)$ & $33(76.7)$ & 0.446 \\
Newborn sex female, n (\%) & $20(57.1)$ & $18(51.4)$ & $22(57.9)$ & 0.835 \\
APGAR $\leq 7$ at 10 min, n (\%) & $0(0)$ & $0(0)$ & $1(2.3)$ & 0.230 \\
Cord blood pH $\leq 7.2, \mathrm{n}(\%)$ & $28(77.8)$ & $27(84.4)$ & $28(70.7)$ & 0.385 \\
Newborn weight, kg & $3,547 \pm 528.7$ & $3,550 \pm 408.8$ & $3,427 \pm 493.6$ & 0.422 \\
Newborn length, cm & $52.3 \pm 2.97$ & $52.1 \pm 1.93$ & $51.3 \pm 2.55$ & 0.094 \\
Newborn head circumference, cm & $35.3 \pm 1.14$ & $35.3 \pm 1.18$ & $35.3 \pm 1.70$ & 0.991 \\
\hline
\end{tabular}

All applicable values are given as mean $\pm \mathrm{SD}$.

No significant difference between groups (one-way ANOVA).

Blood samples of 115 mothers were available by 37 weeks of pregnancy ( $80 \%$ of 142), 89 blood samples at 3 months after delivery (62\%), 78 breast milk samples were obtained of the mothers at 3 months, and because many mothers denied to have blood drawn from their infants, only 50 blood samples could be obtained of their 3month-old infants (43\% of 116 infants) (fig. 1). There was no significant difference in the maternal baseline characteristics (tables 2, 3) between those who remained in the study or had blood samples taken and those who did not participate in the follow-up (data not shown).

DHA, ARA and EPA concentrations in the RBC phospholipids of the mothers at enrolment were not different between the three groups (table 4). But at 37 weeks of gestation as well as at 3 months after delivery RBC-DHA and $\mathrm{RBC}-\mathrm{EPA}$ concentrations were significantly higher in the DHA-FOS group than in the two other groups. RBCARA concentrations were slightly, but not significantly lower in the DHA-FOS group compared to the others (table 4).

The DHA content of the breast milk fatty acids 3 months after delivery was twice as high in the DHA-FOS group than in the two other groups, while the ARA contents were not different (table 4). The ratio ARA/DHA in the DHA-FOS group compared to the two other groups was therefore significantly reduced from $2.1 \pm 0.76$ to $1.0 \pm 0.43(\mathrm{p}<0.001)$. The RBC-DHA concentrations of the infants at 3 months of age in the DHA-FOS group were significantly higher and the ARA concentrations similar to the two other groups (table 3).
The RBC-DHA concentrations increased from pregnancy week 21 to week 37 in the DHA-FOS ( $p<0.001)$, FOS $(\mathrm{p}<0.01)$ and Vit/Min $(\mathrm{p}<0.01)$ groups, and then decreased during lactation. The increase was significantly higher in the DHA-FOS group ( $\mathrm{p}<0.005)$. After delivery, the DHA values decreased in all groups, but the value 3 months after delivery was slightly higher in the DHA-FOS group than the baseline value, though not significantly so, while the values in the other two groups were lower than at baseline.

The RBC-ARA concentrations in the three groups decreased (but not significantly so) from baseline to 37 weeks of gestation, and increased in either group significantly from the concentration at 37 weeks to 3 months after delivery $(\mathrm{p}<0.05)$. Overall, from baseline to 3 months after delivery, a slight but not significant increase in either group was observed.

The RBC-DHA concentrations of the 3-month-old infants showed a significant correlation with the maternal RBC-DHA concentrations at 3 months after delivery (Pearson's $r=0.55, p<0.001$ ), explaining $30 \%$ of the variance (fig. 2a). The correlation of the infants' values with the RBC-DHA concentrations of the mothers at 37 weeks of gestation was also significant (Pearson's $\mathrm{r}=0.34$, $\mathrm{p}<$ 0.05 ), but not with their RBC-DHA at 21 weeks (Pearson's $\mathrm{r}=0.09$, n.s.).

A significant correlation was found between the breast milk DHA concentration of the mothers and their RBCDHA concentrations 3 months after delivery (Pearson's $\mathrm{r}=0.47, \mathrm{p}<0.0001$ ), explaining $23 \%$ of the variance 
Table 4. ITT data set, summary statistics of fatty acid concentrations in the RBC-membrane phospholipids (RBC-FA\%) of mothers and infants and in breast milk lipids (FA\%) by supplement group

\begin{tabular}{lccc}
\hline & Vit/Min & FOS & DHA-FOS \\
\hline Docosahexaenoic acid & & & \\
21 weeks' gestation & $5.76 \pm 2.45(47)$ & $5.94 \pm 2.37(48)$ & $5.69 \pm 2.40(47)$ \\
37 weeks' gestation & $6.93 \pm 2.32(38)$ & $7.08 \pm 2.12(36)$ & $8.48 \pm 2.43(41)^{*}$ \\
3 months' lactation & $5.05 \pm 1.53(27)$ & $5.17 \pm 2.09(30)$ & $6.48 \pm 1.78(32)^{*}$ \\
Infant 3 months & $7.49 \pm 2.00(16)$ & $6.88 \pm 2.76(16)$ & $9.79 \pm 2.21(18)^{*}$ \\
Breast milk 3 months & $0.25 \pm 0.10(24)$ & $0.26 \pm 0.13(25)$ & $0.50 \pm 0.190(29)^{* * *}$ \\
\hline Arachidonic acid & & & \\
21 weeks' gestation & $14.01 \pm 4.04(47)$ & $14.82 \pm 3.60(48)$ & $14.18 \pm 4.32(47)$ \\
37 weeks' gestation & $14.24 \pm 2.87(38)$ & $14.47 \pm 2.72(36)$ & $13.62 \pm 2.50(41)$ \\
3 months' lactation & $15.82 \pm 2.06(27)$ & $15.75 \pm 2.48(30)$ & $14.68 \pm 2.19(32)$ \\
Infant 3 months & $17.80 \pm 2.11(16)$ & $17.31 \pm 3.35(16)$ & $0.47 \pm 0.11(29)$ \\
Breast milk 3 months & $0.48 \pm 0.14(24)$ & $0.47 \pm 0.15(25)$ & $0.79 \pm 0.41(47)$ \\
\hline Eicosapentaenoic acid & & & $0.99 \pm 0.36(41)^{* *}$ \\
21 weeks' gestation & $0.72 \pm 0.32(47)$ & $0.78 \pm 0.38(48)$ & $1.60 \pm 0.47(32)^{* *}$ \\
37 weeks' gestation & $0.67 \pm 0.23(38)$ & $0.76 \pm 0.33(36)$ & $0.95 \pm 0.32(18)^{* *}$ \\
3 months' lactation & $1.22 \pm 0.29(27)$ & $1.17 \pm 0.47(30)$ & $0.13 \pm 0.06(29)^{*}$ \\
Infant 3 months & $0.65 \pm 0.19(16)$ & $0.71 \pm 0.40(16)$ & \\
Breast milk 3 months & $0.09 \pm 0.04(24)$ & $0.09 \pm 0.06(25)$ & \\
\hline \multicolumn{2}{c}{ All values are given as mean \pm SD (n). } & & \\
DHA-FOS group significantly different from Vit/Min and from FOS supplement groups. Group compari- \\
sons performed by ANCOVA, controlling for baseline values: ${ }^{*} \mathrm{p}<0.05 ;{ }^{* *} \mathrm{p}<0.005 ;{ }^{* * *} \mathrm{p}<0.001$. \\
\hline
\end{tabular}

(fig. 2b). The breast milk DHA concentrations were also significantly correlated with the RBC-DHA concentrations of the mothers at 37 weeks of gestation $(r=0.39$, $\mathrm{p}<0.001$ ), but not with her RBC-DHA concentrations at gestational week $21(\mathrm{r}=0.11$, n.s.). When the DHA-FOS group and the groups not receiving DHA were analyzed separately, it could be shown that a significant correlation between breast milk DHA and maternal RBC-DHA at 3 months was found only in the groups not receiving DHA $(\mathrm{r}=0.402, \mathrm{p}<0.005)$, and not in the DHA-FOS group $(\mathrm{r}=0.18$, n.s.).

The correlation between the breast milk DHA and the RBC-DHA concentrations of the infants was only weak $(\mathrm{r}=0.30, \mathrm{p}=0.049)$ (fig. 2c). The fit for the cubic function between these variables was better, but for the sake of clarity the results are not presented.

\section{Discussion}

The results of this study show that the DHA status of pregnant women in Germany, estimated by the DHA fraction of their red blood cell phospholipids, can be improved by providing $200 \mathrm{mg}$ DHA/day, beginning in mid-pregnancy, and that these supplements enhanced the DHA status of their breast-fed infants. Compared to other European countries, fish consumption of German women is low, the mean daily DHA intake of women in childbearing age is below $100 \mathrm{mg} /$ day $[40,41]$. In this study, the pregnant mothers had a relatively high educational level. Their RBC-DHA concentrations at baseline (21 weeks pregnant) were close to the values of women in Missouri/USA (gestational weeks 24-28), in Perth/Australia (gestational weeks 20), and twice as high as in an area of Scotland with a very low fish consumption (gestational weeks 15) $[14,16,42]$. The RBC-EPA values at baseline in our study fit to a moderately low habitual fish consumption of the participants.

At 37 weeks of pregnancy, the RBC-DHA concentrations in the groups with DHA supplementation had increased by $50 \%$ and in the non-DHA supplemented groups by $20 \%$. Several other studies reported an increase in the RBC-DHA concentrations in late pregnancy, especially after supplementation [14-16]. Burdge et al. [43] observed an increase of the DHA content of plasma phosphatidylcholine in pregnancy, and not in other plasma 

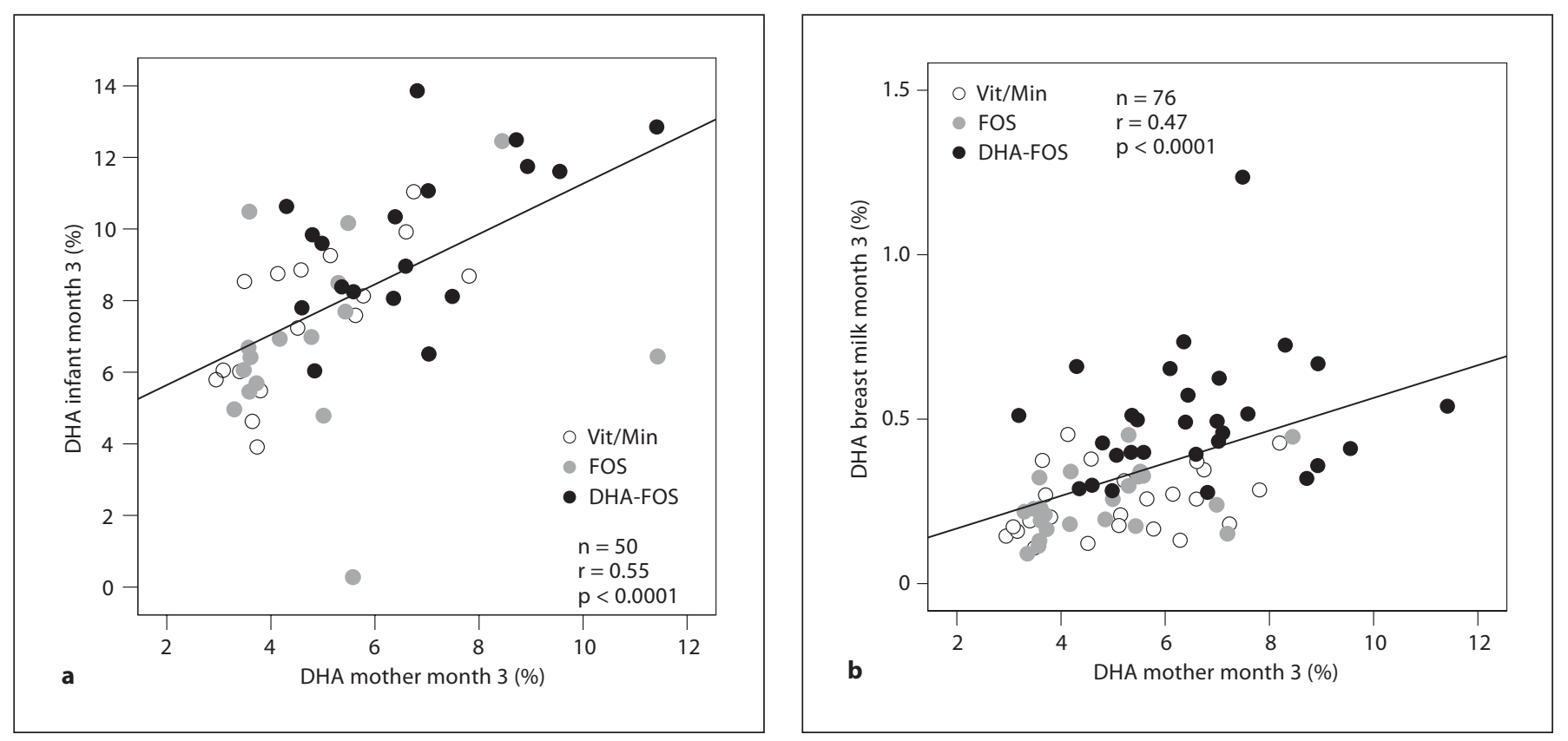

Fig. 2. RBC-DHA (wt\%) of mothers and infants and DHA content in breast milk lipids (wt\%) at 3 months after delivery. $r=$ Pearson correlation coefficient.

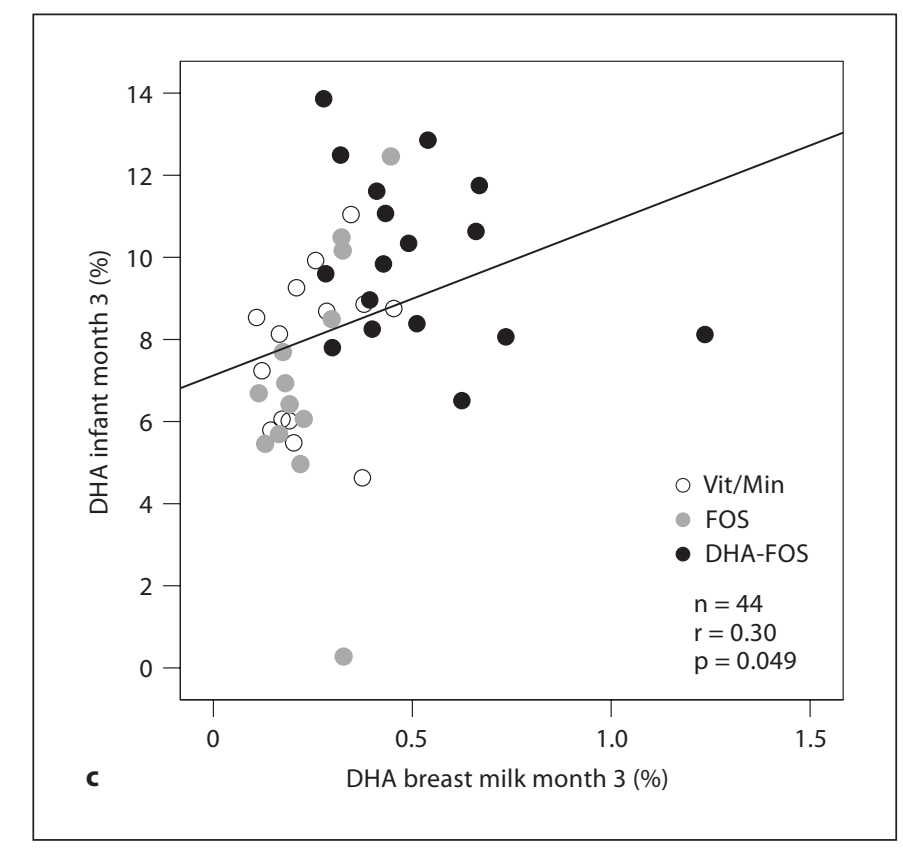

compartments, and interpreted this to reflect a selective enrichment of DHA in special plasma pools in order to increase the bioavailability of this FA to the placenta and the fetus.

Supplementation with probiotics in pregnancy was recently shown to increase the concentration of $\omega-3 \mathrm{FA}$ in placental phospholipids [44]. But the RBC-DHA concentrations of our FOS group increased only slight-

ly and not significantly, compared to the Vit/Min group.

Because of the competition in the metabolism of $\omega-3$ and $\omega-6$ LC-PUFAs (fish-oil supplements containing DHA and EPA may decrease the ARA status of mothers and neonates), we monitored the ARA concentrations [45]. In our study, the RBC-ARA concentrations had not changed very much, they resembled the values in the 
Perth study [16]. The sum of RBC-DHA and RBC-EPA, the so-called $\omega-3$ index of our DHA-supplemented subjects at 37 weeks of pregnancy had reached a value considered to reflect an optimal intake of $\omega-3 \mathrm{FA}[38,46]$.

Three months after birth, the DHA-RBC concentrations of the infants were more closely correlated with the RBC-DHA of the mothers than with breast milk DHA concentrations, suggesting that the intrauterine and early postnatal supply in our study might have been more important than the infants' dietary intake with breast milk. This is in line with the notion that maternal LC-PUFA body stores during pregnancy more than the actual diet influence the LC-PUFA status of the breast milk fatty acid composition [17]. On the other hand, many studies showed that breast milk lipids are acutely influenced by the actual dietary intake of the mother, an effect that lasts 1-2 days [19-29, 47]. A daily supplement leads to gradually increasing values in breast milk, which reach a steady state after 1 week of supplementation [48].

The breast milk DHA was on average from $0.5 \%$ of FA in our DHA-supplemented mothers to $0.25 \%$ of FA in the non-DHA-supplemented groups, which corresponds to average values found in habitually moderately high fish consumers and of low fish consumers, respectively [18]. Likewise, the breast milk EPA concentrations in our study fit to the pattern of relatively high and low fish consumers, respectively. The ratio ARA/DHA in the groups not receiving DHA was 2.1, which corresponds to the values reported in countries like Australia, Canada and the USA [49]. In the DHA group, the ratio was 1.0, which is close to the ratios found in Denmark, Norway, and the UK (calculated from $[18,49]$ ), but lower than in countries with a high fish consumption like Japan and the Philippines [49].

The distribution of the scatter plots in figure $2 \mathrm{c}$ suggests that with breast milk DHA concentrations above i.e. these infants might have acquired a good DHA nutrifant RBC-DHA and breast milk DHA, and a plateau of data. The fit was statistically significant, and the correla-

tion coefficient even higher than with the linear fit, which supports the concept of saturation.

Likewise, a saturation phenomenon in the DHA-supplemented mothers may explain why the breast milk DHA concentrations depend on maternal RBC-DHA concentrations at 3 months after delivery only in the groups not receiving DHA, indicating that marginal DHA stores after delivery are found more often in these mothers.

In a follow-up study, we found a lower BMI in these infants at the age of 21 months [36]. This favorable outcome together with the presented DHA values in RBC and breast milk indicate that in a population with a relatively low fish consumption, i.e. a dose of $200 \mathrm{mg} /$ day DHA from mid-pregnancy through lactation, seems to be appropriate to improve the DHA status of pregnant and lactating women and their infants.

\section{Acknowledgements}

R.L. Bergmann wrote the first manuscript, all of the authors participated in the interpretation of the data and in the final manuscript. F. Haschke developed the study design, P. Klassen-Wigger participated in the study development. R.L. Bergmann was responsible for the recruitment of subjects, data collection, and together with J.W. Dudenhausen for the project management. E. Haschke-Becher developed the methods of the LC-PUFA analysis and was responsible for the analytical quality. R. Richter and D. Grathwohl did the statistical analysis in cooperation with K.E. Bergmann, who also was a significant advisor.

We thank Dr. Iris Baldauf, Dr. Lisa Grünewald, and Dr. Friederike Taraz, who helped in the collection of the data, and Dr. Marianna Giarrè ${ }^{\dagger}$, who did the monitoring of the study. We appreciate and thank the obstetricians who permitted us to recruit the participants in their offices. We thank all the families for their participation and compliance. $0.5 \%$, no increase of infant RBC-DHA values is observed, tional status, whereas especially infants in the nonsupplemented groups with their lower RBC-DHA concentrations still depend on the DHA supply from breast milk. These findings are in line with an Australian study on maternal DHA supplementation during lactation: the authors found a saturation in the relationship between inthe RBC-DHA concentrations at $0.8 \%$ FA in breast milk $[22,48]$. In an attempt to test the concept of saturation in our own smaller data set, we fitted a cubic function to our

\section{References}

1 IOM (Institute of Medicine), National Academy of Sciences: Nutrition during Pregnancy. Washington, National Academy Press, 1990.

2 Picciano MF: Pregnancy and lactation: physiological adjustments, nutritional requirements and the role of dietary supplements. J Nutr 2003;133:1997S-2002S

-3 Allen LH: Multiple micronutrients in pregnancy and lactation: an overview. Am J Clin Nutr 2005;81:1206S-1213S.

-4 Glenville M: Nutritional supplements in pregnancy: commercial push or evidence based? Curr Opin Obstet Gynecol 2006;18: 642-647. 
5 Roberfroid MB: Concepts and strategy of functional food science: The European perspective. Am J Clin Nutr 2000;71:1660S$1664 \mathrm{~S}$

$\checkmark 6$ Calder PC, Krauss-Etschman S, de Jong EC, Dupont C, Frick JS, Heinrich J, Garn H, Koletzko S, Lack G, Matelio G, Renz H, Sangild PT, Schrezenmair J, Stulnig TM, Thymann T, Wold AE, Koletzko B: Early nutrition and immunity: progress and perspectives. $\mathrm{Br} \mathrm{J}$ Nutr 2006;96:774-790.

$\checkmark 7$ Krauss-Etschmann S, Shahid R, Campoy C, Hoster E, Demmelmair H, Jiménez M, Gil A, Rivero M, Veszprémi B, Decsi T, Koletzko BV, Nutrition and Health Lifestyle (NUHEAL) Study Group: Effects of fish-oil and folate supplementation of pregnant women on maternal and fetal plasma concentrations of docosahexaenoic acid and eicosapentaenoic acid: a European randomized multicenter trial. Am J Clin Nutr 2007;85:13921400.

-8 Crawford MA, Hassan AG, Williams G: Essential fatty acids and fetal brain growth. Lancet 1976;i:452-459.

$\checkmark 9$ Makrides M, Neumann M, Simmer K, Pater J, Gibson R: Are long-chain polyunsaturated fatty acids essential nutrients in infancy? Lancet 1995;345:1463-1468.

10 Haggarty P: Effect of placental function on fatty acid requirements during pregnancy. Eur J Clin Nutr 2004;58:1559-1570.

-11 Herrera E, Amusquivar E, Lopez-Soldado I, Ortega $\mathrm{H}$ : Maternal lipid metabolism and placental lipid transfer. Horm Res 2006;65: S59-S64.

12 Holman RT, Johnson SB, Osburn PL: Deficiency of essential fatty acids and membrane fluidity during pregnancy and lactation. Proc Natl Acad Sci USA 1991;88:48354839.

$\checkmark 13$ Otto SJ, van Houwelingen AC, Antal M, Manninen A, Godfrey K, Lopez-Jaramillo P, Hornstra G: Maternal and neonatal essential fatty acid status in phospholipids: an international comparative study. Eur J Clin Nutr 1997;51:232-242.

-14 Montgomery C, Speake BK, Cameron A, Sat$\operatorname{tar}$ N, Weaver LT: Maternal docosahexaenoic acid supplementation and fetal accretion. Br J Nutr 2003;90:135-145.

- 15 Otto SJ, van Houwelingen AC, Hornstra G: The effect of supplementation with docosahexaenoic and arachidonic acid derived from single cell oils on plasma and erythrocyte fatty acids of pregnant women in the second trimester. Prostaglandins Leukotr Essential Fatty Acids 2000;63:323-328.

-16 Dunstan JA, Mori TA, Barden LJ, Holt PG, Calder PC, Taylor AL, Prescott SL: Effects on n-3 polyunsaturated fatty acid supplementation in pregnancy on maternal and fetal erythrocyte fatty acid composition. Eur J Clin Nutr 2004;58:429-437.
17 Koletzko B, Rodriguez-Palmero M, Demmelmair H, Fidler N, Jensen R, Sauerwald T: Physiological aspects of human milk lipids. Early Hum Dev 2001;65:S3-S18.

18 Lauritzen L, Hansen HS, Jörgensen MH, Michaelsen KF: The essentiality of long chain n-3 fatty acids in relation to development and function of brain and retina. Prog Lipid Res 2001;40:1-94.

19 Harris WS, Connor WE, Lindsey S: Will dietary omega-3 fatty acids change the composition of human milk? Am J Clin Nutr 1984; 40:780-785.

20 Henderson RA, Jensen RG, Lammi-Keefe CJ, Ferris AM, Dardick KR: Effect of fish oil on the fatty acid composition of human milk and maternal and infant erythrocytes. Lipids 1992;27:863-869.

21 Cherian G, Sim JS: Changes in the breast milk fatty acids and plasma lipids of nursing mothers following consumption on $n-3$ polyunsaturated fatty acid enriched eggs. Nutrition 1996;12:8-12.

22 Makrides M, Neumann MA, Gibson RA: Effect of maternal docosahexaenoic acid (DHA) supplementation on breast milk composition. Eur J Clin Nutr 1996;50:352357.

23 Jensen CL, Maude M, Anderson RE, Heird WC: Effect of docosahexaenoic acid supplementation of lactating women on the fatty acid composition of breast milk lipids and maternal and infant plasma phospholipids. Am J Clin Nutr 2000;71:292S-299S.

24 Jensen CL, Voigt RG, Prager TC, Zou YL, Fraley JK, Rozelle JC, Turcich MR, Llorente AM, Anderson RA, Heird WC: Effects of maternal docosahexaenoic acid intake on visual function and neurodevelopment in breastfed term infants. Am J Clin Nutr 2005;82:125132.

25 Fidler N, Sauerwald Th, Pohl A, Demmelmair H, Koletzko B: Docosahexaenoic acid transfer into human milk after dietary supplementation: a randomized clinical trial. J Lipid Res 2000;41:1376-1383.

26 Boris J, Jensen B, Salvig JD, Secher JD, Olsen SF: A randomized controlled trial of the effect of fish oil supplementation in late pregnancy and early lactation on the $n-3$ fatty acid content in human breast milk. Lipids 2004,39:1191-1196.

27 Helland IB, Saarem K, Saugstad OD, Drevon CA: Fatty acid composition in maternal milk and plasma during supplementation with cod liver oil. Eur J Clin Nutr 1998;52:839845 .

28 Helland IB, Smith L, Saarem K, Saugstad OD, Drevon CA: Maternal supplementation with very long-chain $n-3$ fatty acids during pregnancy and lactation augments children's IQ at 4 years of age. Pediatrics 2003;111:e39e44.
29 Lauritzen L, Hoppe C, Straarup EM, Michaelsen KF: Maternal fish oil supplementation in lactation and growth during the first 2.5 years of life. Pediatr Res 2005;58:235242.

30 Simopoulos AP, Leaf A, Salem N: Conference report: workshop on the essentiality of and recommended dietary intakes for omega-6 and omega-3 fatty acids. J Am Coll Nutr 1999;18:487-489.

31 Akabas SR, Deckelbaum RJ: Summary of a workshop on n-3 fatty acids: current status of recommendations and future direction. Am J Clin Nutr 2006;83:1536S-1538S.

32 Koletzko B, Cetin I, Thomas Brenna J, the Perinatal Lipid Intake Working Group: Dietary fat intakes for pregnant and lactating women. Br J Nutr 2007;98:873-877.

33 Gibson GR, Roberfroid MB: Dietary modulation of the human colonic microbiota: Introducing the concept of prebiotics. J Nutr 1995;125:1401-1412.

34 Gibson GR: Dietary modulation of the human gut microflora using prebiotics. Br J Nutr 1998;80:S209-S212.

35 Fukushima M, Yamada A, Endo T, Nakano M: Effect of a mixture of organisms, lactobacillus acidophilus or streptococcus faecalis on $\Delta$-3-desaturase activity in the livers of rats fed a fat- and cholesterol-enriched diet. Nutrition 1999;15:373-378.

36 DACH, Deutsche Gesellschaft für Ernährung, Österreichische Gesellschaft für Ernährung, Schweizerische Gesellschaft für Ernährung, Schweizerische Vereinigung für Ernährung: Referenzwerte für die Nährstoffzufuhr. Frankfurt (Main), Umschau/ Braus, 2000.

37 Bergmann RL, Haschke-Becher E, Bergmann KE, Richter R, Dudenhausen JW, Barclay D, Haschke F: Does maternal docosahexaenoic acid supplementation during pregnancy and lactation lower BMI in late infancy? J Perinat Med 2007;35:295-300.

38 Geppert J, Kraft V, Demmelmair H, Koletzko B: Docosahexaenoic acid supplementation in vegetarians effectively increases the n-3 index: a randomized trial. Lipids 2005; 40:807-814.

39 Innis SM: Essential fatty acid transfer and fetal development. Placenta 2005;26(suppl 19): S70-S75.

40 Welch AA, Lund E, Amiano P, et al: Variability of fish consumption within the 10 European countries participating in the European Investigation into Cancer and Nutrition (EPIC) study. Public Health Nutr 2002;5: 1273-1285.

41 DGE (Deutsche Gesellschaft für Ernährung): Ernährungsbericht 2004. Bonn, DGE, 2004.

42 Smuts CM, Huang M, Mundy D, Plasse T, Major S, Carlson SE: A randomized trial of docohexaenoic acid supplemention during third trimester of pregnancy. Obstet Gynecol 2003;101:469-479. 
43 Burdge GC, Sherman RC, Ali Z, Wootton SA, Jackson AA: Docosahexaenoic acid is selectively enriched in plasma phospholipids during pregnancy in Trinidad women: results of a pilot study. Reprod Nutr Dev 2006; 46:63-67.

44 Kaplas N, Isolauri E, Lampi A-M, Ojala T, Laitinen K: Dietary counseling and probiotic supplementation during pregnancy modify placental phospholipid fatty acids. Lipids 2007;42:865-870.
45 Van Houwelingen AC, Sørensen JD, Hornstra G, Simonis MMG, Boris J, Olsen SF, Secher NJ: Essential fatty acid status in neonates after fish-oil supplementation during pregnancy. Br J Nutr 1995;74:723-731.

46 Harris WS, von Schacky C: The omega-3 index: a new risk factor for death from coronary heart disease? Prevent Med 2004;39: 212-220.

47 Francois CA, Connor SL, Wander RC, Connor WE: Acute effects of dietary fatty acids on the fatty acids of human milk. Am J Clin Nutr 1998;67:301-308.
48 Gibson RA, Neumann MA, Makrides M: Effect of increasing breast milk docosahexaenoic acid on plasma and erythrocyte fatty acids and neural indices in exclusively breast fed infants. Eur J Clin Nutr 1997;51:578574.

9 Yuhas R, Pramuk K, Lien EL: Human milk fatty acid composition from nine countries varies most in DHA. Lipids 2006;41:851858. 